CZASOPISMO INŻYNIERII LA¿DOWEJ, ŚRODOWISKA I ARCHITEKTURY JOURNAL OF CIVIL ENGINEERING, ENVIRONMENT AND ARCHITECTURE

JCEEA, t. XXXIII, z. 63 (1/II/16), styczeń-marzec 2016, s. 401-408

Adam ZOFKA ${ }^{1}$

Maciej MALISZEWSKI ${ }^{2}$

Dominika MALISZEWSKA ${ }^{3}$

\title{
BADANIE MIESZANEK MINERALNO- ASFALTOWYCH W WARUNKACH ŚCINANIA PRZY KONTROLOWANEJ SZTYWNOŚCI WZDŁUŻNEJ
}

\begin{abstract}
W artykule przedstawiono koncepcję nowej metody badania próbek z mieszanki mineralno-asfaltowej w warunkach ścinania z ciśnieniem bocznym. Dotychczas stosowane metody badawcze ścinania z obciążeniem bocznym opierają się na ocenie właściwości mieszanki mineralno-asfaltowej przy ścinaniu w warunkach stałej siły wzdłużnej lub stałej objętości badanej próbki. Nowa metoda badawcza pozwala na badanie ścinania przy stałej sztywności wzdłużnej. Aby możliwe było badanie według tej metody, zaprojektowano i wykonano specjalną przystawkę o nazwie AST (ang. Advanced Shear Tester). W artykule przedstawiono zarówno opis procesu twórczego podczas projektowania przystawki, jak wykonane urządzenie. Zaprezentowano pierwsze wyniki badań walidacyjnych uzyskanych przy użyciu przystawki na próbkach UHMW-PE oraz z mieszanki mineralno-asfaltowej.
\end{abstract}

Słowa kluczowe: właściwości mechaniczne, reologia, nowe metody

\section{Wstęp}

\subsection{Informacje ogólne}

Laboratoryjna ocena właściwości mieszanek mineralno-asfaltowych jest od dziesięcioleci przedmiotem wielu prac badawczych. Rzeczywista konstrukcja poddawana jest złożonym obciążeniom, których nie sposób jest w pełni zasymulować w warunkach laboratoryjnych, a każdorazowa budowa odcinka badawczego w skali rzeczywistej nie ma uzasadnienia ekonomicznego i czasowego. $\mathrm{Z}$ tego powodu wykonuje się badania laboratoryjne, które mają na celu określenie cech fundamentalnych materiałów (takich jak moduł sprężystości, moduł odkształcenia postaciowego, współczynnik Poisson'a, odporność na zmęczenie,

\footnotetext{
${ }^{1}$ Autor do korespondencji/corresponding author: Adam Zofka, Instytut Badawczy Dróg i Mostów, ul. Instytutowa 1, 03-302 Warszawa, 223900 407, azofka@ibdim.edu.pl

${ }^{2}$ Maciej Maliszewski, Instytut Badawczy Dróg i Mostów

${ }^{3}$ Maciej Maliszewski, Instytut Badawczy Dróg i Mostów
} 
itp.) lub cech powiązanych funkcjonalnie (odporność na działanie wody i mrozu, odporność na koleinowanie, itp.). Na podstawie cech mechanicznych ocenionych laboratoryjnie można przewidzieć zachowanie konstrukcji w warunkach rzeczywistych. Również projektowanie trwałości i nośności konstrukcji drogowej jest przedmiotem wielu prac badawczych. Możliwe jest różnorakie podejście do zagadnienia projektowania konstrukcji nawierzchni, m.in. metody obliczeniowe opierające się na wynikach stanu naprężenia i odkształcenia w wielowarstwowej półprzestrzeni sprężystej lub też metody opierające się na obliczeniach metodą elementów skończonych. Bez względu na sposób przeprowadzenia obliczeń, istotną rolę odgrywa zjawisko ścinania występujące na styku pomiędzy warstwami konstrukcyjnymi nawierzchni lub w obrębie warstwy. Osłabienie połączenia warstw powoduje obniżenie nośności konstrukcji [1], [2]. Zjawisko ścinania może mieć charakter monotoniczny doprowadzający do zniszczenia materiału ze względu na wystąpienie jednorazowych naprężeń niszczących, bądź cykliczny, którego pojedyncze wystąpienia nie powodują uszkodzenia materiału, ale powtarzalne wystąpienia prowadzą do zniszczenia materiału ze względu na zmęczenie. Prekursorem badań wytrzymałości na ścinanie połączenia międzywarstwowego był Leutner [3] a inni usprawniali bądź modyfikowali opracowaną przez niego metodę [4]. Następnie opracowywano bardziej zaawansowane urządzenia badawcze np. do badań ścinania z zastosowaniem ciśnienia bocznego lub badań zmęczeniowych połączenia międzywarstwowego [5].

Przejazd pojedynczego koła pojazdu nie ogranicza się jedynie do występowania nacisku pionowego na nawierzchnię, ale wywołuje złożony stan naprężenia, obejmujący również siły ścinające [6]. Wartość sił ścinających zależy od głębokości i odległości od przejeżdżającego koła [7].

Na podstawie studium literatury można stwierdzić, że ocena pracy mieszanek mineralno-asfaltowych (mm-a) w warunkach ścinania może być prowadzona na różne sposoby, m.in. poprzez:

- skręcanie [8],

- rozciąganie [9],

- rozłupywanie [10],

- ścinanie bezpośrednie [3].

Ocenę można przeprowadzać bez udziału siły poprzecznej do kierunku ścinania lub z udziałem tej siły [11]. Badania mogą być wykonywane przy kontrolowanym przesuwie podczas ścinania lub przy kontrolowanej sile ścinania.

$\mathrm{W}$ badaniach właściwości mechanicznych $\mathrm{w}$ warunkach ścinania $\mathrm{z}$ siłą poprzeczną do powierzchni ścinania można wyróżnić 4 zasadnicze schematy badawcze:

- badanie przy braku obciążenia wzdłużnego,

- badanie przy stałej objętości (ang. constant volume),

- badanie przy stałej sztywności (ang. constant normal stiffness),

- badanie przy stałej sile wzdłużnej (ang. constant normal load). 


\subsection{Koncepcja nowej metody badawczej}

Założenia do nowej metody badawczej przyjęto na podstawie analizy literatury i dotychczasowych doświadczeń związanych z metodami badawczymi ścinania mieszanek mineralno-asfaltowych. Większość urządzeń badawczych pracujących w trybie ścinania wykonana była w schemacie obciążenia przy stałej objętości, przy stałej sile wzdłużnej lub bez obciążenia wzdłużnego. Na tle tych metod badawczych, nowa metoda przedstawiona w niniejszym artykule jest innowacyjna w skali światowej. Zastosowano tu bowiem nie stosowany wcześniej $\mathrm{w}$ badaniach $\mathrm{mm}$-a schemat pracy $\mathrm{w}$ trybie bezpośredniego ścinania i schemacie obciążenia ze stałą sztywnością wzdłużną. Urządzenie pod nazwą AST (ang. Advanced Shear Tester) zostało od podstaw zaprojektowane i wykonane w IBDiM [12].

Motywacją do stworzenia tego unikalnego aparatu była fundamentalna analiza zagadnienia nacisku od koła poruszającego się pojazdu na nawierzchnię. Pracę urządzenia AST można przyrównać do oddziaływania pojazdu poruszającego się po nawierzchni z uwzględnieniem sił od nacisku, hamowania i pracy zawieszenia oraz opon. Takiemu schematowi odpowiada schemat badania przy stałej sile wzdłużnej, który został zastosowany w aparacie AST. Schemat koncepcyjny przedstawiono na rysunku 1 .

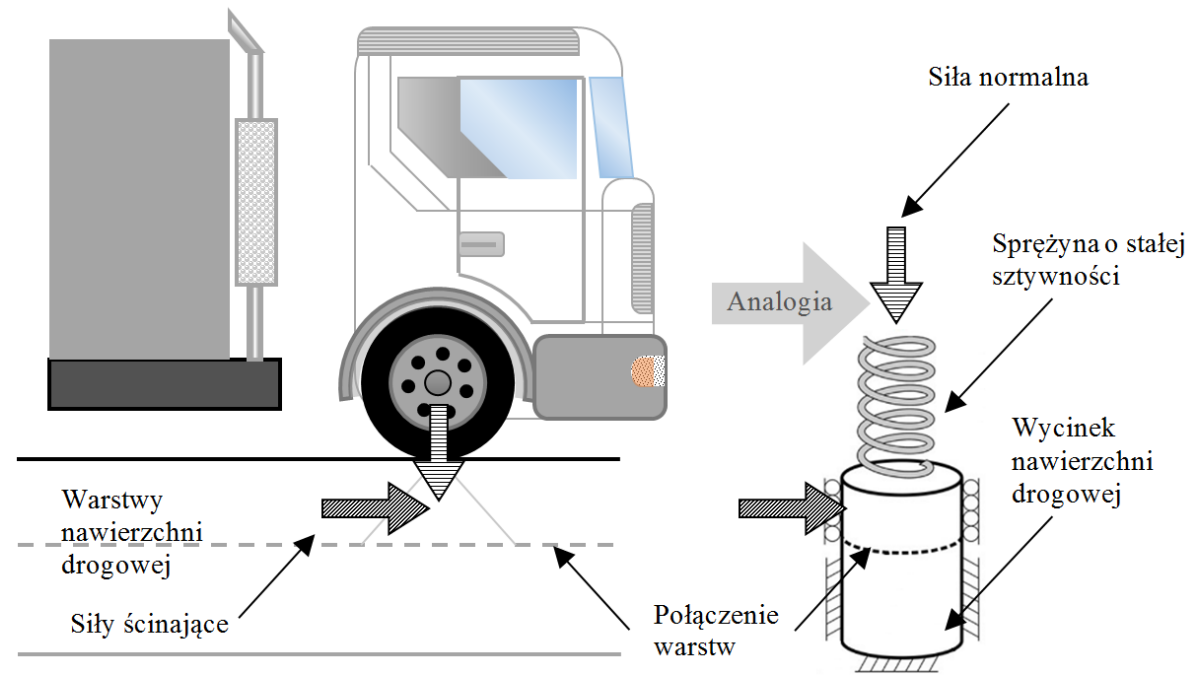

Rys. 1. Schemat ideowy oraz statyczny działania aparatu AST

Fig. 1 Schematic and static overview of AST device

Urządzenie AST zostało opracowane w formie przystawki, którą można zamontować w prasie wytrzymałościowej, w komorze termostatycznej. Możliwości badawcze przystawki zależą od możliwości prasy wytrzymałościowej, na której została zamontowana. Ze wstępnych szacunków wynika, że prasa wytrzymało- 
ściowa powinna mieć minimalną nośność $50 \mathrm{kN}$. W przypadku montażu przystawki AST na urządzeniu MTS w IBDiM urządzenie może pracować w trybie:

- monotonicznym, dwukierunkowym, realizując badania wytrzymałościowe,

- cyklicznym, dwukierunkowym, realizując badania zmęczeniowe,

- kontrolowanego przemieszczenia lub siły,

- w/w tryby mogą być realizowane bez obciążenia wzdłużnego lub z obciążeniem wzdłużnym w zakresie do $300 \mathrm{kPa}$.

Badane próbki mają kształt cylindryczny o średnicy ok. $150 \pm 5 \mathrm{~mm}$ i wysokości $250 \pm 100 \mathrm{~mm}$. Odległość pomiędzy płaszczyznami ścinania można regulować w zakresie 5,10 i $15 \mathrm{~mm}$. W przypadku zastosowania obciążenia bocznego o stałej sztywności wzdłużnej, jej wartość można zmieniać poprzez zmianę sprężyn dociskowych o liniowej charakterystyce sztywności dostosowanej do przewidywanej odpowiedzi badanego materiału, np. $\mathrm{k}=1,654 \mathrm{kN} / \mathrm{mm}$. Unikalną cechą aparatu jest również możliwość kontrolowania zjawiska dylatacji, czyli ekspansji badanego materiału podczas ścinania na skutek jego granularnej budowy. Przedstawione cechy stanowią o jego unikalnych właściwościach.

Schemat urządzenia badawczego AST przedstawiono na rysunku 2.

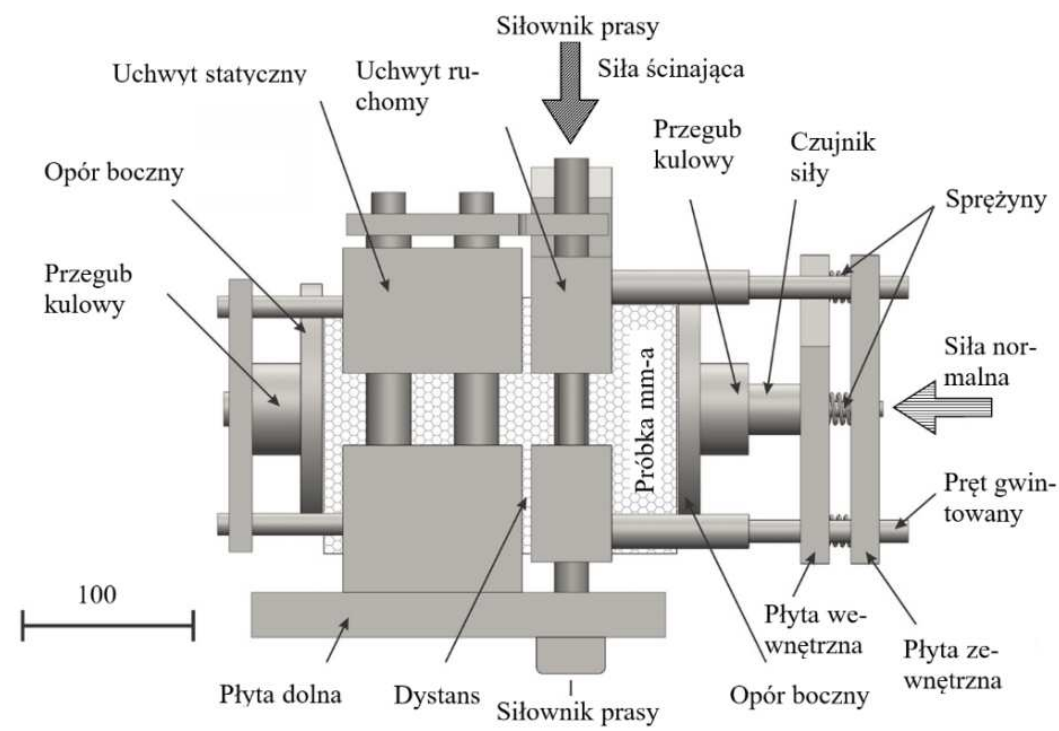

Rys. 2. Szczegółowy schemat budowy aparatu AST

Fig. 2. Schematic design of AST device

Do wykonania korpusu urządzenia wykorzystano stal kwasoodporną, a stal utwardzana posłużyła do wykonania elementów prowadzących i łączących. Do wykonania elementu obciążającego o stałej sztywności wykorzystano seryjnie produkowane sprężyny oraz tensometryczny czujnik siły. Fotografię gotowego do pracy urządzenia przedstawiono na rysunku 3. 


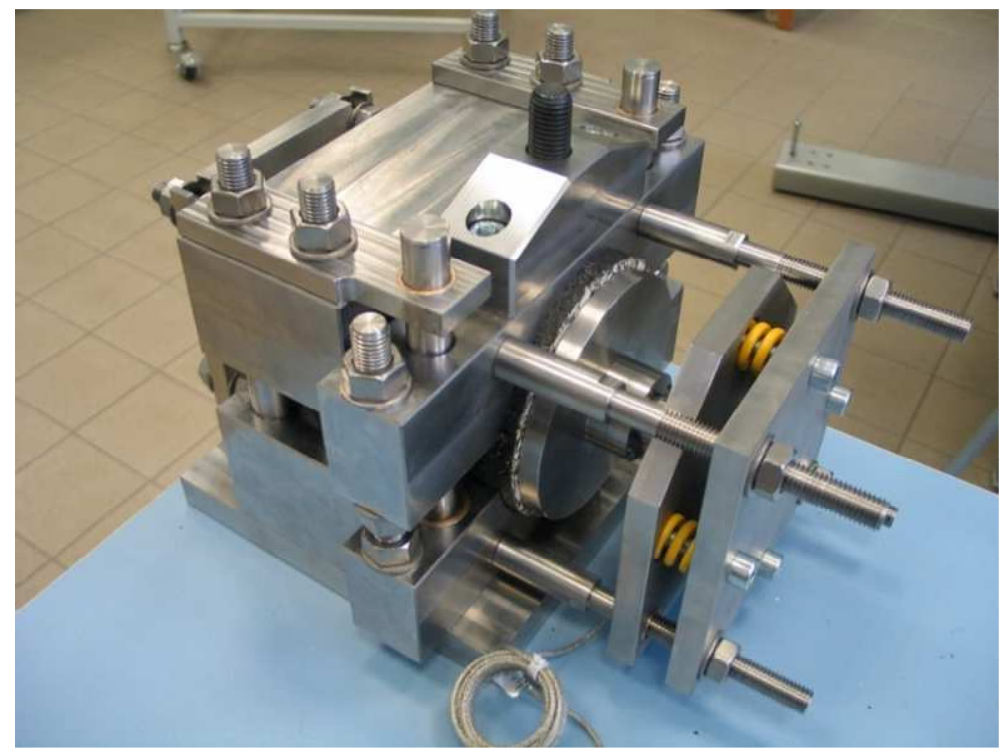

Rys. 3. Urządzenie AST gotowe do badań

Fig. 3. AST device ready for testing

\section{Ocena możliwości badawczych urządzenia AST}

Ocenę możliwości badawczych nowego urządzenia można realizować np. wykonując badania fundamentalnej cechy materiału o znanych i udokumentowanych właściwościach mechanicznych, bądź porównując wyniki badań z rezultatami uzyskanymi przy wykorzystaniu innych znanych i rozpoznanych metod badawczych. Jeśli przyjęto poprawne założenia przy projektowaniu nowego urządzenia i zostało ono poprawnie skonstruowane powinno być możliwe uzyskanie analogicznych cech materiałowych bez względu na stosowaną metodę badania. Mieszanka mineralno-asfaltowa jest materiałem reologicznie złożonym. W zależności od temperatury dominują w niej pewne cechy charakterystyczne, tj. w niskich temperaturach dominują cechy sprężyste, w średnich temperaturach cechy lepko-sprężyste, a w wysokich temperaturach cechy lepko-plastyczne. Próbki z mm-a wykazują cechy anizotropowe przede wszystkim z uwagi na aspekty technologiczne procesu ich przygotowania, nie powinny być zatem wykorzystywane jako jedyny materiał do oceny możliwości badawczych nowego urządzenia. W celu przeprowadzenia walidacji nowo wykonanego urządzenia pomiarowego można wykorzystać polietylen o ultra wysokiej gęstości cząsteczkowej (UHMW-PE), który wykazuje cechy lepko-sprężyste przy ortotropowej budowie wewnętrznej. 
Do oceny możliwości badawczych aparatu AST przewidziano przygotowanie zestawu próbek cylindrycznych i pryzmatycznych o różnych wymiarach, przeznaczonych do przeprowadzenia badań alternatywnymi metodami.

Wstępne badania w aparacie AST wykonano na próbkach z UHMW-PE o średnicy $150 \mathrm{~mm}$ i wysokości $200 \mathrm{~mm}$ przy różnych częstotliwościach $(0,1$, $0,2,0,5,1,2,5,10,20$ i $30 \mathrm{~Hz})$, amplitudach przemieszczenia $(0,01,0,02,0,05$, $0,1 \mathrm{~mm})$ i zmiennym ciśnieniu bocznym $(50,150$ i $300 \mathrm{kPa})$. Badania wykonano w trybie nieniszczącym, w zakresie odkształceń lepko-sprężystych. Wyniki tych oznaczeń przedstawiono na rysunku 4.

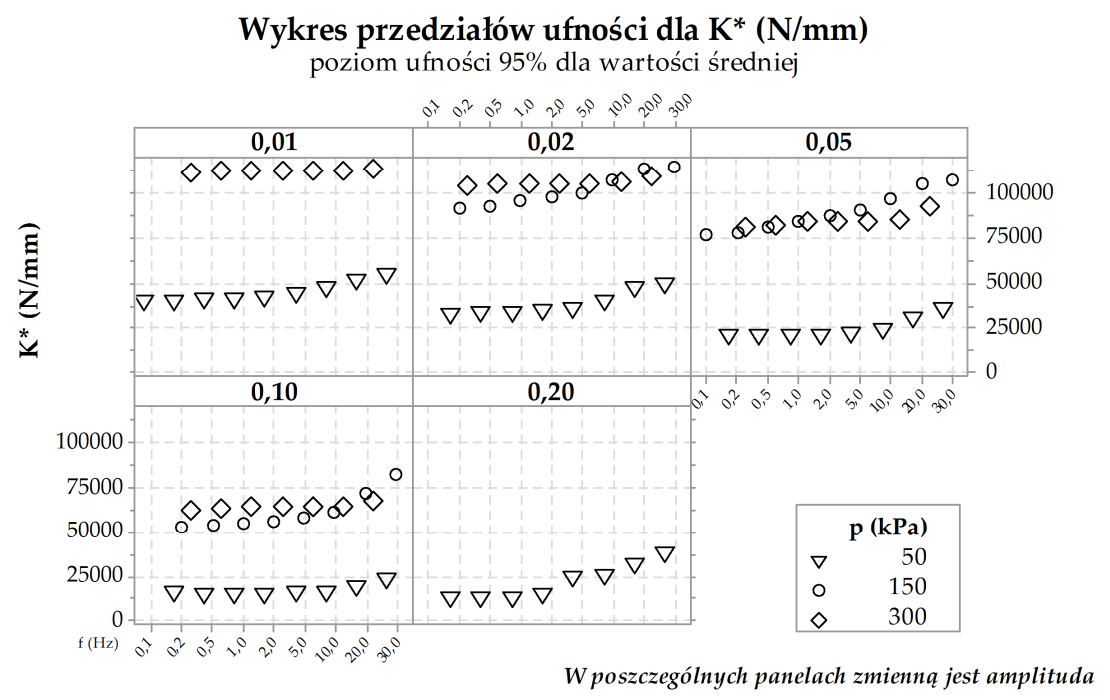

Rys. 4. Wykres przedziałów ufności dla sztywności zespolonej $\mathrm{K}^{*}(\mathrm{~N} / \mathrm{mm})$ próbek UHMW-PE w funkcji zmiennej częstotliwości f (Hz) (pozioma oś kategorii), amplitudy A $(\mathrm{mm})$ (poszczególne panele) oraz ciśnienie boczne p $(\mathrm{kPa})$

Fig. 4. Interval plot for complex stiffness $K^{*}(\mathrm{~N} / \mathrm{mm})$ UHMW-PE specimens vs. frequency $\mathrm{f}(\mathrm{Hz})$ (horizontal category domain), amplitude $\mathrm{A}(\mathrm{mm})$ (adequate panels) and normal pressure $\mathrm{p}(\mathrm{kPa})$

Z przeprowadzonych wstępnych badań wynika, że aparat był w stanie pracować w zakresie częstotliwości do $20 \mathrm{~Hz}$ i amplitudzie do $0,1 \mathrm{~mm}$, przy czym wyższe częstotliwości badawcze i amplitudy wymagają dopracowania metody. Zastosowanie ciśnienia bocznego podnosiło wyniki sztywności zespolonej badanej próbki.

Po przeprowadzeniu badań próbek UHMW-PE wykonano pilotażowe badania próbek z mm-a przy różnych warunkach obciążenia. Z badań tych wynikły podobne zależności, tzn. odpowiedź materiału rozkładała się płasko w funkcji amplitudy i częstotliwości obciążenia. 


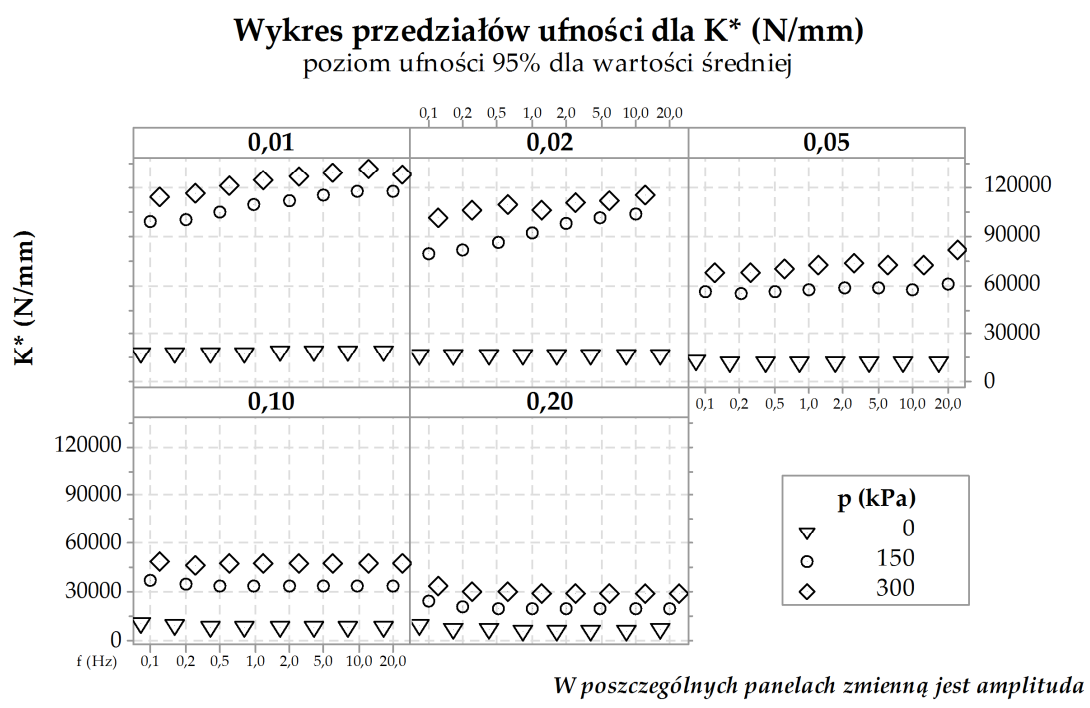

Rys. 5. Wykres przedziałów ufności dla sztywności zespolonej $\mathrm{K}^{*}(\mathrm{~N} / \mathrm{mm})$ próbek mm-a w funkcji zmiennej częstotliwości f (Hz) (pozioma oś kategorii), amplitudy A $(\mathrm{mm})$ (poszczególne panele) oraz ciśnienie boczne $\mathrm{p}(\mathrm{kPa})$

Fig. 5. Interval plot for complex stiffness $\mathrm{K}^{*}(\mathrm{~N} / \mathrm{mm})$ of Hot Mix Asphalt specimens vs. frequency $\mathrm{f}(\mathrm{Hz})$ (horizontal category domain), amplitude $\mathrm{A}(\mathrm{mm})$ (adequate panels) and normal pressure $\mathrm{p}(\mathrm{kPa})$

\section{Plany badawcze}

Planowane jest wykonanie szerokich badań próbek z UHMW-PE i mm-a w celu scharakteryzowania właściwości tych materiałów i odniesienia do obecnie stosowanych metod. Planowane jest wykonanie badań modułu rozciągania pośredniego według IT-CY, modułu ściskania/rozciągania UCT oraz sprowadzenie właściwości uzyskanych w tych badaniach do wartości zastępczych.

\section{Literatura}

[1] S. F. Brown and J. M. Brunton, "The influence of bonding between bituminous layers," J. Inst. Highw. Transp., vol. 31, pp. 16-17, 1984.

[2] P. JASKUŁA, "Wpływ braku sczepności międzywarstwowej na wartość modułów warstw asfaltowych obliczanych na podstawie ugięć," Drogownictwo, pp. 13-17, 2010.

[3] R. Leutner, "Untersuchungen des Schichtenverbunds beim bituminösen Oberbau [Investigation of the Adhesion of Bituminius Pavements]," Bitumen, vol. 3, pp. 84-91, 1979.

[4] C. Raab and M. N. Partl, "Methoden zur beurteilung des schichtenverbunds von asphaltbelägen," 1999.

[5] J. Sousa, M. Solaimanian, and S. Weissman, "Development and Use of the Repeated Shear Test (Constant Height): An Optional Superpave Mix Design Test," 1994. 
[6] R. V Siddharthan, J. Yao, and P. E. Sebaaly, "Pavement strain from moving dynamic 3D load distribution,” J. Transp. Eng., vol. 124, no. 6, pp. 557-566, 1998.

[7] A. Zofka, M. Maliszewski, A. Bernier, R. Josen, A. Vaitkus, and R. Kleiziené, "Advanced shear tester for evaluation of asphalt concrete under constant normal stiffness conditions," Road Mater. Pavement Des., vol. 16, no. sup1, pp. 187-210, May 2015.

[8] M. Diakhaté, C. Petit, A. Millien, B. Phelipot-Mardelé, A. Pouteau, and H. Goacolou, "Comparison of direct shear and torque tests for determining viscoelastic shear behavior of tack coats," in Proceeding of the international conference on advanced characterization of pavement and soil engineering materials, 2007, pp. 281-90.

[9] S. Hakimzadeh, W. G. Buttlar, and R. Santarromana, "Shear- and Tension-Type Tests to Evaluate Bonding of Hot-Mix Asphalt Layers with Different Tack Coat Application Rates," Transp. Res. Rec. J. Transp. Res. Board, vol. 2295, no. -1, pp. 54-62, Dec. 2012.

[10] H. N. Linsbauer and E. K. Tschegg, "Fracture energy determination of concrete with cube shaped specimens," Zement und Bet., no. 31, pp. 38-40, 1986.

[11] M. P. Divakar and A. Fafiti, "Micromechanics-Based Constitutive Model for Interface Shear," J. Eng. Mech., vol. 118, no. 7, pp. 1317-1337, 1986.

[12] A. Zofka, A. Bernier, R. Josen, and M. Maliszewski, "Advanced Shear Tester for Solid and Layered Samples," in Proceedings of 12th International Society for Asphalt Pavements Conference, 2014.

\section{HOT MIX ASPHALT SHEARING TEST METHOD IN CONSTANT NORAL STIFFNESS CONDITIONS}

\section{S u m m a r y}

The concept of new test method in shear mode with normal load was presented in this article. Present methods are based on constant normal load and constant volume test mode. The new test method utilizes constant normal stiffness mode. Special device called AST (Advanced Shear Tester) was designed to meet the test conditions. Both motivation and design process was described in article. Preliminary test results on UHMW-PE and hot mix asphalt specimens were also presented.

Keywords: mechanical properties, rheology, new test method

Przestano do redakcji: 07.06.2016 r.

Przyjęto do druku: 30.06.2016 r.

DOI: $10.7862 / \mathrm{rb} .2016 .100$ 